\title{
A Review of New Zealand's Digital Strategy
}

\author{
Andy Williamson \\ Wairua Consulting Limited $<$ andy@wairua.co.nz $>$
}

\begin{abstract}
The advent of New Zealand's world-leading Digital Strategy underpins the increasing importance of ICTs in community settings. It also marks a significant change in government policy and the first time a government has adopted a whole of government approach to ICTs. This article provides a personal view of the policy process for creating the Digital Strategy, presented by one of the participants in that process. It contextualises the Digital Strategy in CI initiatives in Aotearoa/New Zealand, and identifies important issues attending its implementation and future.
\end{abstract}

\section{Introduction}

The advent of New Zealand's world-leading Digital Strategy underpins the increasing importance of ICTs in community settings. It also marks a significant change in government policy and the first time a government has adopted a whole of government approach to ICTs. As the introduction to the Digital Strategy says, it is about Aotearoa/New Zealand becoming "a world leader in using information and technology to realise its economic, social, environmental and cultural goals, to the benefit of all its people" (New Zealand Government, 2005, p. 4). In order to contextualise the Digital Strategy, this article will look briefly at the context for Community Informatics (CI) initiatives in Aotearoa/New Zealand, identifying the issues facing such projects. It then goes on to position the new Digital Strategy from its evolution as a draft strategy, through a consultation process to the final release. It will describe some of the ideas behind the strategy, the processes for its implementation (where these are known) and some of the potential limitations, including a project-centric focus and a lack of framework for implementation. Finally, the funding made available to CI initiatives through the strategy is discussed.

By necessity, this is a brief (and personal) review of the Digital Strategy. You can read the strategy for yourself at www.digitalstrategy.govt.nz. You can also read another perspective, by Williams, Sligo and Wallace, in this issue of the Journal of Community Informatics.

\section{The Aotearoa/New Zealand Context}

Many local CI initiatives exist in Aotearoa/New Zealand, including literacy and training, access to websites, telecentres, management tools and discussion forums. Many of these appear highly successful and some world-leading and local research indicates that ICTs are improving outcomes for stakeholders of community organisations by making services more inclusive and accessible (Craig, Dashfield, \& Thomson, 2003; Craig \& Williamson, 2005). Research indicates that local CI initiatives tend to be over-reliant on goodwill and voluntary resources and, because of this, their existence can be perilous (Day, 2004). This is certainly the case in New Zealand and a primary issue must be workforce development (using the term in its broadest sense). In a recent summary of four of my own CI research projects (Williamson, 2005), I identified key themes across the projects: Funding; access; planning and partnerships. 


\section{Funding}

Funding is a significant concern for most community-based projects. Problems associated with funding have a flow-on effect in terms of the sustainability of the project and with regards to staffing, training and the acquisition of appropriate and up-to-date equipment. ICTs are now considered to be 'core business' by many community-based organisations, yet funding is still in most cases only available on a project-byproject basis.

\section{Access}

Appropriate and timely access to ICTs is an obvious need and there is a clear requirement in New Zealand to provide solutions that can bridge socioeconomic divides, allowing all citizens who wish to use ICTs to be able to access them. It is not simply access that is important but the immediacy of that access in terms of fully utilising ICTs for both personal and community activities.

\section{Planning}

Planning is seen as important to the success of CI projects. However, the over-reliance on volunteers coupled with a lack of funding means that there is seldom the time or skills available in a CI project to do sufficient planning. Solutions must be planned and outcomes described and agreed upon at the community level. A top-down approach does not work well for community ICTs. This points to an obvious need to share knowledge and information about initiatives; not only those that are successful but the lessons to learn from those that are not. It suggests a need for a 'knowledge base' or 'toolkit of ideas' but does not promote the flawed idea of 'best practice' or a one-size-fits all approach.

\section{Partnerships}

If resources are limited, then sustainability is difficult to obtain. A solution to this is to encourage the sharing of ideas and resources and to support the building of partnerships that can offer sustainability. Such partnerships can exist between community-based organisations, local government, central government and the NGO sector. Where communities can work together, additional benefits and economies of scale can be realised (Williamson, 2003). If the Digital Strategy is to succeed, it must address these four themes.

\section{Locating $\mathrm{CI}$ in a Policy Context}

The potential value of CI was first recognised at a policy level through the Connecting Communities Strategy (Community Employment Group, 2002), which aimed to improve access to, and the effective use of, ICTs amongst communities. More recently, the Draft Digital Strategy and, evolving from that, the newly released Digital Strategy (New Zealand Government, 2004, 2005) have been developed to "provide an integrated framework for existing and future initiatives to encourage the uptake and effective use of ICTs for economic, social and cultural gain"(New Zealand Government, 2004, p. 2). It is significant because it sets the policy and funding agendas for CI initiatives in Aotearoa/New Zealand. The Digital Strategy signals a realisation that a whole of government approach to ICT is required and that, even in a 'developed' country such as New Zealand, ubiquity and sustainability of ICT, or innovation through ICT, cannot be assumed. The model used in the strategy is internationally significant because it is has emerged after the First World Summit on the Information Society (WSIS, 2004) and adopts the WSIS tri-sectoral model of government, business and civil society (or community).

The Draft Digital Strategy (New Zealand Government, 2004) was a discussion document, setting out what the government thought it needed to do. Publication of this document was followed by significant consultation with business, government and community stakeholders through meetings, presentations and the opportunity to make written submissions. It was my personal opinion that the Draft Digital Strategy was an excellent first step but that it was weak in a number of areas. Particularly, an overt focus on 
replicating 'best practice' risked being paternalistic and limiting, and no attempt was made to address the ongoing sustainability of CI initiatives. Perhaps the greatest omission was the lack of any tangible delivery mechanism. These issues are addressed to some degree in the final Digital Strategy (New Zealand Government, 2005).

\section{The Digital Strategy}

The final version of the Digital Strategy is surprisingly brief. It (rightly) refrains from repeating much of the background information present in the Draft strategy, instead focussing on the way forward. The Digital Strategy addresses social and cultural good, however, there is significant emphasis on economic benefit. In this regard it differs from traditional approaches to the digital divide, which identify exclusion as a primarily social problem (Thomson \& Craig, 2004). The Digital Strategy builds on the Draft strategy by describing an ongoing funding mechanism for project-based initiatives. Whilst it is not clear how the fund will operate at this early stage, an Advisory Group has been formed and it is evident that a framework will need to be developed to manage the allocation of funding. Whereas, in this regard, the Draft strategy appeared laissez-faire and subjective, the final strategy is a significant improvement but still fails to explicitly promote frameworks for evaluating outcomes or effectiveness. However, it appears anecdotally that this might be remedied in the implementation. The naïve and somewhat flawed assumption that what works in one location will be successful in another, inherent in the Draft strategy, is gone in the final version. This is fortunate since CI initiatives generally disprove the myth of 'best practice'; they are not the result of technological determinism but of the appropriate social construction of technology in a specific and localised context (Williamson, 2003). One problem remaining in the Digital Strategy is the lack of any distinction between projects and ICTs as a 'business as usual' component of communities. Whilst the Digital Strategy does provide project-based funding, it still does little to address how projects can become operationalized and sustainable. Unfortunately, the economic model privileged in the Digital Strategy reinforces a short-term approach to competitive funding and the high risk of technocratic/bureaucratic intervention on a project basis at the expense of sustainability and operationalisation. As Day (2004) cautions, this short-term approach has historically been detrimental to CI initiatives and it is hoped that this issue can be resolved in the implementation. Particularly significant in this regard is the appointment of an Advisory Board who can promote the importance of long-term sustainability.

\section{Funding for CI projects}

Words and grand ideas are one thing. Money is quite another. Fortunately, the Digital Strategy does contain significant new funding allocations for CI related initiatives. It is evident that New Zealand lacks the fiscal and economic resources to fund projects on the same scale as Canada and the UK; we are simply too small. However, it is often said that what we lack in dollars we can make up for in ingenuity and commitment. This is, perhaps, the key driver behind the funding component of the Digital Strategy. The key here is partnership: Partnership is a key component underpinning the new Digital Strategy and is perhaps the best opportunity for individual communities to achieve effective solutions with limited resources. Funding will be provided to projects that can demonstrate working partnerships between communities, government agencies or the private sector. This implies that funding is to seed what has already been evaluated as a viable initiative and will hopefully ensure that sustainability can be achieved. For CI initiatives, there are two key funds:

- Broadband Challenge: NZ $\$ 24 \mathrm{~m}$ of contestable funding to support partnerships to deploy openaccess fibre networks.

- Community Partnership Fund: NZ\$20.7m of contestable funding to build capacity in communities and develop strong local partnerships.

In addition, NZ $\$ 1.44 \mathrm{~m}$ is available for remote areas to access broadband and some funding remains in the Connecting Communities strategy. This is significant and real money going into CI initiatives for the first time in New Zealand. 


\section{Impact on Research}

The Digital Strategy will require an evaluation framework to monitor money spent and this presents CI researchers both locally and internationally with an opportunity to influence what good CI research means. Successful community informatics projects are embedded within communities and support the aspirations of the community that they serve (Day, 2003). Research and evaluation is important for learning and sharing. It is itself an aspect of partnership. However, it is of critical importance in a community-based setting that the researchers are seen as participants in the process as well as observers within the study. This process is like "paddling a waka [canoe] alongside [the community]" (Williamson \& DeSouza, 2003, p. 20 ), acknowledging our own role as guests but also developing relationships with the participants. This approach is consistent with that recommended by Guba and Lincoln, who promote that "participants [are] accorded the privilege of sharing their constructions and working toward a common, consensual, more fully informed and sophisticated, joint construction, [where] they [are] accorded a full measure of conceptual parity" (Guba \& Lincoln, 1989, p. 11). In particular, we need to promote the value of rigorous qualitative research and the use of participant's stories as being equally as important as more traditional quantitative studies.

\section{Conclusion}

Whilst it is still early days the Digital Strategy is an exciting document that offers significant potential for CI practitioners and researchers in Aotearoa/New Zealand. The Digital Strategy is a whole of government approach to ICTs and the Advisory Group will advise and, hopefully, influence a number of Ministers and Ministries. This presents us with a serious opportunity to increase the importance and knowledge of ICTs in developing our communities through a broader policy setting. At the grassroots, the Strategy appears to support locally emerging solutions and partnerships that can lead to sustainability. It contains funding for access and education, which are critical if all sectors of society are to be brought along. Whilst there are some limitations, this is to be expected in such a new and wide-ranging strategy. The pattern so far has been one of evolution through consultation and it is hoped that this process will continue, allowing the Strategy to be fine tuned as it is rolled out.

This Digital Strategy clearly has the potential to position Aotearoa/New Zealand as a world leader in $\mathrm{CI}$ initiatives. It offers direct solutions to issues of funding and access and, through the promotion of partnerships that can lead to increased collaboration and better skills, it supports long-term sustainability. Whilst only time will tell whether this works, I suspect that what we do next will be watched very closely.

\section{References}

Community Employment Group. (2002). Connecting communities: A strategy for government support of community access to Information and Communications Technology. Wellington, NZ: Department of Labour.

Craig, B., Dashfield, B., \& Thomson, I. (2003). Community information and communication technology research report. Wellington, NZ: Victoria University of Wellington.

Craig, B., \& Williamson, A. (2005). Survey of New Zealand community ICT organisations and projects. Wellington, NZ: Victoria University of Wellington/Department of Labour.

Day, P. (2003). Community (information and communication) technology: Policy, partnership and practice. In S. Marshall, W. Taylor \& Y. Xinghuo (Eds.), Using Community Informatics to Transform Regions. Melbourne, VIC: Idea Group.

Day, P. (2004, Sept 29 - Oct 1). Building and sustaining health communities: The symbiosis between community technology and community research. Paper presented at the Community Informatics Research Network Conference and Colloquium, Prato, Italy. 
Guba, E., \& Lincoln, Y. (1989). Fourth generation evaluation. California: Sage Publications.

New Zealand Government. (2004). Digital Strategy: A draft New Zealand strategy for consultation. Wellington, NZ: New Zealand Government.

New Zealand Government. (2005). The Digital Strategy: Creating our digital future. Wellington, NZ: New Zealand Government.

Thomson, I., \& Craig, B. (2004, Sept 29 - Oct 1). New Zealand's Digital Strategy - A Case Study Workshop. Paper presented at the Community Informatics Research Network Conference and Colloquium, Prato, Italy.

Williamson, A. (2003). Shifting the centre: The Internet as a tool for community activism. In S. Marshall \& W. Taylor (Eds.), Proceedings of the 5th International Information Technology in Regional Areas (ITiRA) Conference (pp. 149-155). Rockhampton, QLD: Central Queensland University.

Williamson, A. (2005, June 21). What we've learned from community informatics research in New Zealand. Paper presented at the 2020 Communications Trust's Thematic Seminar on Community ICT Research, Victoria University, Wellington, NZ.

Williamson, A., \& DeSouza, R. (2003). Evaluation of the Otara Digital Opportunities Project. Auckland, NZ: CITRUS/Wairua Consulting Ltd.

WSIS. (2004). World summit on the information society. Retrieved Aug 21, 2004, from http://www.itu.int/wsis 